\title{
Formação de Professores no Setor de Educação da Universidade Federal do Paraná (1938-2010)
}

\author{
Carlos Eduardo Vieira' \\ Nadia Gaiofatto Gonçalves' \\ 'Universidade Federal do Paraná (UFPR), Curitiba/PR - Brasil
}

RESUMO - Formação de Professores no Setor de Educação da Universidade Federal do Paraná (1938-2010). O objetivo do artigo é narrar a história do processo de formação de professores em nível superior no Estado do Paraná, tendo como fio condutor da análise aspectos relacionados à criação da primeira instituição de ensino superior do Estado, designada a partir de 1950, como Universidade Federal do Paraná (UFPR). Enfatizaremos as mudanças nas configurações institucionais, políticas e curriculares associadas aos diferentes espaços acadêmicos envolvidos nos processos de formação de professores na UFPR, entre 1938 e 2010. Especial atenção será dedicada à implantação e consolidação do curso de Pedagogia e do Setor de Educação, ainda que, pontualmente, analisaremos propostas e ações relacionadas aos cursos de licenciatura presentes na instituição.

Palavras-chave:Formação deProfessores.UFPR.Curso dePedagogia.Licenciaturas.

ABSTRACT - Teacher Training in the Education Sector of Universidade Federal do Paraná (1938-2010). This article is intended to convey the history of the process of teacher training at the higher education level in Paraná state. The conducting thread of the analysis are aspects related to the creation of the first higher education institution in the state, known since 1950 as Universidade Federal do Paraná (UFPR). We will emphasize the changes in the institutional, political and curricular configurations associated with the different academic aspects involved in the teacher training processes at UFPR between 1938 and 2010. Special attention will be dedicated to the implementation and consolidation of the pedagogy course and the Education Sector, and we will analyze proposals and actions related to the teacher training courses at the institution.

Keywords: Teacher Training. UFPR. Pedagogy Course. Licentiate Degree Courses.

Educação \& Realidade, Porto Alegre, v. 41, n. especial, p. 1441-1464, dez. 2016. 1441 http://dx.doi.org/10.1590/2175-623667656 


\section{Introdução}

O objetivo deste artigo é problematizar a formação de professores em nível superior no Estado do Paraná, tendo como foco principal aspectos relacionados à história da Universidade Federal do Paraná (UFPR). Esta instituição, criada em 1950, representa a culminância de um processo iniciado em 1912 e que demarcou a implantação do ensino superior no Estado do Paraná. Considerando os contextos da Faculdade de Filosofia Ciências e Letras (FFCL) e do Setor de Educação (SE) analisaremos as mudanças institucionais, políticas e curriculares ocorridas entre os anos de 1938 e 2010, com ênfase na implantação e consolidação do curso de Pedagogia, ainda que, pontualmente, abordaremos questões relacionadas aos cursos de licenciatura.

O processo de implantação do ensino superior no Estado pode ser sumarizado em cinco momentos. O primeiro remete para o projeto defendido pelo historiador e político José Francisco da Rocha Pombo, apresentado em 1892 e que previa a formação de uma escola superior no Paraná. Rocha Pombo assistiu a sua ideia se tornar lei estadual e, a partir dela, recebeu a concessão do Estado para que ele administrasse a instituição, que seria criada na cidade de Curitiba. Esta proposição previa a incorporação da Escola Normal, fundada em 1876, ao projeto universitário, de maneira que a formação de professores se tornaria parte dos objetivos do ensino superior. Porém, a falta de apoio político, seja de Rocha Pombo em relação à elite política do Estado ou do próprio Estado em relação ao governo federal, concorreram para o malogro da proposta.

O segundo momento foi a criação da Universidade do Paraná (UP), em 1912. O desenho institucional da UP se apoiava em três faculdades: Direito, que incluía o curso de Comércio; Engenharia, que incluía o curso de Agronomia; e Medicina, que continha os cursos de Obstetrícia, Odontologia, Cirurgia, Farmácia e Medicina Veterinária. A implantação da universidade não previa investimentos nas áreas de humanidades e, por consequência, na formação de professores em nível superior. O terceiro momento foi a criação da Faculdade de Filosofia, Ciências e Letras do Paraná (FFCL-PR), em 1938. Esta instituição supriu as lacunas de formação do projeto de 1912, uma vez que esta instituição, completamente independente da UP, se dedicou às ciências puras e às humanidades, representadas pela Física, Química, Biologia, Letras Clássicas e Modernas, História e Filosofia, além da Pedagogia. O quarto está representado pela união, em uma mesma instituição superior, da UP e da FFCL, em 1946, que adotou a denominação, originária de 1912, de Universidade do Paraná. A convergência dos grupos e dos projetos universitários conduziu à campanha bem-sucedida pela federalização da instituição que, a partir de 1950, passou a denominar-se Universidade Federal do Paraná (UFPR), demarcando o início do quinto momento destacado nesta síntese e que representou a consolidação da instituição em termos de financiamento, estrutura acadêmica e figura jurídica.

1442 Educação \& Realidade, Porto Alegre, v. 41, n. especial, p. 1441-1464, dez. 2016. 
Esse breve roteiro do processo de institucionalização da primeira instituição de ensino superior no Estado, sinaliza para o leitor a cronologia e o cenário geral em que pretendemos inserir este artigo. Não obstante, deve ficar claro que não investiremos na interpretação detalhada destes momentos específicos, pois isto nos distanciaria muito do objetivo desse artigo, além do que as obras escritas por Wachowicz (2006), Westphalen (1987; 1988), Campos (2008) e Vieira e Campos (2013) discutiram em detalhes as questões relacionadas a essas instituições.

Considerando este quadro geral, faremos, na primeira parte deste artigo, uma breve análise da criação da FFCL, pois foi nesta instituição que identificamos a emergência do projeto de formação de professores em nível superior. Na segunda parte verticalizaremos a análise para o Curso de Pedagogia e os processos associados à formação de professores que perpassaram a história da FFCL, bem como, já no contexto da UFPR, da Faculdade de Educação (1970) e do Setor de Educação (1973), que se constituíram como os lugares onde preponderaram as práticas e as reflexões associadas aos processos de formação de professores.

\section{Faculdade de Filosofia, Ciências e Letras do Paraná: formando professores em nível superior ${ }^{1}$}

O projeto da FFCL estava associado ao movimento de organização do laicato católico que - desde a fundação em Curitiba do Círculo de Estudos Bandeirantes (CEB), em 1929 - inicia uma reação à propagação do anticlericalismo e da visão de mundo materialista na cidade de Curitiba. Na proposta da nova organização de ensino, a filosofia ocupava um papel central e, não por acaso, o antecedente da FFCL foi o curso de filosofia tomista, ministrado entre os anos de 1934 e 1937, pelo Pe. Jesus Ballarin. O curso teve como frequentadores Liguarú Espírito Santo, José Loureiro Fernandes, Bento Munhoz da Rocha Neto, entre outros intelectuais que se engajaram na militância católica na primeira metade do século XX. O final do século XIX foi, particularmente, difícil para a posição dos católicos, já que a atmosfera materialista e anticlerical dos primeiros anos de República contribuiu para a afirmação de propostas que objetivavam a secularização do Estado e da sociedade. Nesse sentido, entendemos a FFCL como parte de uma estratégia da Igreja Católica, representada pelo seu laicato, para recuperar terreno na formação da visão de mundo das elites políticas e culturais.

Segundo Westphalen (1988, p. 19), o corpo docente que fundou a FFCL era composto por 31 professores oriundos das Faculdades de Direito, Engenharia e Medicina da UP, da Escola Agronômica do Paraná, do Círculo de Estudos Bandeirantes, além de alguns sacerdotes católicos. A solenidade de fundação ocorreu no dia 26 de fevereiro de 1938, no Salão Nobre do prédio da UP. Nessa ocasião, foi eleita a primeira diretoria: Diretor, Omar Gonçalves da Mota; Vice-Diretor, Carlos de Paula Soares; e Secretário, Homero de Melo e Braga (Anuário..., 1940/1941, p. 5).

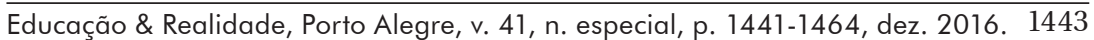


A primeira conclusão a que chegamos é que a FFCL contou com o apoio da UP para a realização dos seus movimentos iniciais. Essa colaboração pôde ser sentida quando a FFCL foi desalojada sumariamente da sua sede provisória, o Congresso Legislativo Estadual, em função de divergências entre o Diretor da Faculdade e Manoel Ribas, Interventor do Estado (Westphalen, 1988, p. 21). Enquanto a UP contou com grande apoio dos Presidentes de Estado ao longo dos anos 1910 e 1920, nos anos 1930 o interventor getulista não envidou esforços na sustentação dos projetos da UP e da FFCL (Wachowicz, 2006; Westphalen, 1988). Na ausência de um lugar para se estabelecer, a FFCL passou a funcionar provisoriamente no prédio da UP. As limitações financeiras, comuns aos empreendimentos universitários no Paraná, foram parcialmente sanadas em 1939, quando a União Brasileira de Educação e Ensino (UBEE), ligada diretamente à congregação dos irmãos maristas, passou à condição de mantenedora da faculdade. Esse movimento fez daquilo que era implícito, uma realidade explícita, ou seja, a instituição estava "solidamente alicerçada na austera disciplina do cristianismo", mas sem a "rigidez cadavérica de organismos inadaptáveis” (Anuário..., 1943, p. 89). Essa afirmação, extraída dos documentos da FFCL, revela a retórica contraofensiva dos católicos, uma vez que os movimentos anticlericais insistiram no anacronismo e na incapacidade do catolicismo de lidar com o progresso do mundo moderno, apoiado na ciência e na razão. Com essa afirmação eles visavam mostrar que aquela entidade era espaço de manutenção da tradição católica, porém isso não significava incapacidade de aceitar e, sobretudo, de participar ativamente da inovação, do progresso material e do desenvolvimento científico da sociedade.

Após o breve período nas instalações do Palácio da Luz, assim como Romário Martins chamou a sede da UP, a FFCL passou a funcionar no prédio da UBEE, entre as Ruas XV de Novembro e Marechal de Deodoro. Ironicamente a instituição que professava a visão católica de mundo, tão questionada nos primeiros anos de República, estava agora literalmente inserida entre dois símbolos republicanos. O controle da FFCL pelos maristas foi justificado pela falta de condições financeiras para o funcionamento da instituição, porém fica claro que a relação com a igreja incluía motivações filosóficas e ideológicas.

A primeira reorganização da FFCL ocorreu menos de um ano depois de fundada, ao passo que o Decreto Federal, n. 1.190, de 4 abril de 1939 (Brasil, 1939), instituía um novo padrão nacional para a formação de docentes para o ensino normal e secundário, a partir da remodelação da Faculdade Nacional de Filosofia. As mudanças foram parte do processo de transformação da Universidade do Rio de Janeiro em Universidade do Brasil, sob a liderança de Gustavo Capanema. A FFCL paranaense agilmente adaptou-se à nova normatização e elegeu como Diretor o Professor Brasil Pinheiro Machado, que permaneceu no cargo de forma ininterrupta de 1939 a 1951 . O Vice-Diretor eleito, em sintonia com a nova mantenedora e com os intelectuais do Círculo de Estudos 
Bandeirantes, foi o Pe. Jesus Ballarin, mentor filosófico do laicato católico paranaense ${ }^{2}$. Homero de Melo Braga, oriundo da primeira diretoria, foi mantido como secretário.

A participação direta da igreja na gestão e na administração da FFCL implicou em um número cada vez maior de padres e de leigos católicos ministrando disciplinas nos diferentes cursos. Foi a partir do final da década de 1920 que os católicos, por meio do seu laicato, passaram a lutar efetivamente pelo controle do ensino superior no Brasil. Naquele momento, de acordo com Salem (1982, p. 128), para os clericais a reforma na "[...] consciência das elites só se operacionalizaria, basicamente, através do sistema de ensino superior. Ou seja, a cosmovisão católica percebe a universidade como centro nevrálgico de toda a estrutura social". Os católicos se aproximavam do Estado a fim de manter a presença de sua visão de mundo nas instituições públicas e, ao mesmo tempo, participavam diretamente da rede particular de ensino. Em outros termos, não dispensavam a boa relação com o Estado, mas também não acreditavam absolutamente na aliança com o poder civil. Em 1934, no Rio de Janeiro, a igreja organizou o Primeiro Congresso Católico de Educação, no qual Alceu de Amoroso Lima, expressão nacional do laicato militante, reiterava o papel dos católicos na organização de instituições de ensino superior. Dessa forma, percebemos nos anos 1930 uma significativa movimentação do laicato no sentido de formação de faculdades, de maneira que a FFCL no Paraná pode ser entendida no interior dessa estratégia de conquista da consciência das elites intelectuais no Brasil. A FFCL representou um espaço importante de formação, ao passo que se ocupou com as ciências puras, as humanidades, a educação e, particularmente, a filosofia.

A posição católica, embora interessada em um projeto político e ideológico bem definido, contribuiu decisivamente em três direções importantes. Primeiramente na relativização da ideologia cientificista, encarnada de maneira exemplar pelos intelectuais positivistas. Esses proclamavam a ciência como solução para todos os males e, em nome dela, justificavam suas ações, muitas vezes despóticas, em nome do combate à ignorância e à superstição. A segunda contribuição vem na direção da afirmação das humanidades no contexto cultural da cidade de Curitiba, particularmente materializadas nos departamentos de Filosofia e de Letras que organizaram, entre os anos de 1938 e 1946, os cursos de Ciências Sociais, História e Geografia, Filosofia, Letras Clássicas e Neolatinas. A terceira está representada pela contribuição da FFCL na formação de professores no Paraná, visto que é a primeira instituição a formar professor em nível superior. Antes da FFCL o Estado e a iniciativa privada dispunham apenas dos normalistas formados em nível secundário e dos leigos habilitados para o magistério pelos exames de suficiência. No primeiro projeto da FFCL foi criado, anexo à faculdade, o Instituto Superior de Educação (ISE), tendo como responsável a normalista Annete Macedo. O ISE não se concretizou, porém a FFCL, readap-

Educação \& Realidade, Porto Alegre, v. 41, n. especial, p. 1441-1464, dez. 2016. 1445 
tada à legislação em 1939, oferecia, além do Bacharelado em Pedagogia, o Curso de Didática ${ }^{3}$. Esse curso, com duração de um ano, oportunizava aos bacharéis dos diferentes cursos oferecidos pela FFCL a possibilidade de se tornarem licenciados para o magistério no ensino secundário.

\section{Pedagogia e Licenciaturas nos Contextos Institucionais da FFCL e do Setor de Educação da UFPR}

O curso de Pedagogia previa a seguinte grade curricular no seu processo de implantação:

\section{Quadro 1 - Disciplinas Obrigatórias dos Cursos do Departamento de Pedagogia (1939)}

\begin{tabular}{|c|}
\hline Pedagogia -3 anos \\
\hline $\begin{array}{l}1^{\text {o: }} \text { Complementos de Matemática; História da Filosofia; Sociologia; Fund. } \\
\text { Biológicos da Ed.; Psicologia da Ed.. }\end{array}$ \\
\hline $\begin{array}{l}2^{\circ} \text { : Estatística Educacional; História da Ed.; Fund. Sociológicos da Ed.; Psicologia; } \\
\text { Adm. Escolar. }\end{array}$ \\
\hline 3: História da Ed.; Psicologia da Ed.; Adm. Escolar; Ed. Comparada; Filosofia da Ed. \\
\hline Didática -1 ano \\
\hline $\begin{array}{l}\text { Didática Geral; Didática Especial; Psicologia Educacional; Adm. Escolar; Fund. } \\
\text { Sociológicos da Ed. }\end{array}$ \\
\hline Formação de Professores Primários -2 anos $^{4}$ \\
\hline 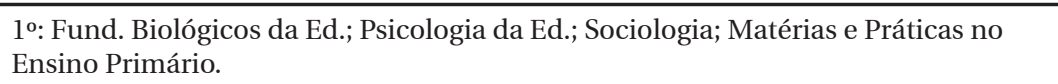 \\
\hline $\begin{array}{l}2^{\circ} \text { : Fund. Biológicos da Ed.; Psicologia Educacional; História e Filosofia da Ed.; Ed. } \\
\text { Comparada; Matérias e Práticas no Ens. Primário. }\end{array}$ \\
\hline
\end{tabular}

Fonte: Adaptado de Glaser (1989).

De acordo com Costa (2012, p. 24):

O Curso de Pedagogia formava nesta época, bacharéis e licenciados, com o modelo de três anos de bacharelado mais um ano de licenciatura (conhecido como o modelo $3+1$ ), sendo a última formação realizada no Curso de Didática. Os bacharéis atuariam como técnicos de educação e os licenciados poderiam atuar como professores da Escola Normal, responsável pela formação dos professores primários.

A prática dos alunos de Didática era realizada em “[...] estabelecimentos oficiais de ensino da Capital, sobretudo, no Colégio Estadual do Paraná e no Instituto de Educação do Paraná” (Westphalen, 1988, p. 46).

Nele [Colégio Estadual do Paraná] em caráter obrigatório, passaram a realizar a prática docente os alunos do curso de Didática [...]. 'O acordo estabeleceu para os alunos-mes-

1446 Educação \& Realidade, Porto Alegre, v. 41, n. especial, p. 1441-1464, dez. 2016. 
tres, um estágio didático. O trabalho técnico-pedagógico consistia de observação pessoal da aula, pré-prática docente e prática de docência' (Glaser, 1989, p. 17).

Entre as finalidades da FFCL se destacavam:

[...] preparar Professores para o ensino médio e superior, administradores escolares, orientadores e técnicos de educação e ensino; e colaborar com instituições congêneres, livres ou oficiais, para levantamento do nível intelectual e moral do professorado (Glaser, 1989, p. 15-16).

Além disso, o Regimento Interno da Faculdade estabeleceu

[...] que os cursos de graduação passassem a compreender um curso fundamental e um curso de licenciatura - o de Didática.

O curso fundamental, com currículo fixo de disciplinas de três anos de duração, era destinado ao preparo de professores do ensino médio, de acordo com a legislação em vigor, abrangendo Química, História Geral, Geografia, História, Ciências Sociais, Letras Clássicas, Letras Neolatinas, Letras Anglo-Germânicas, Pedagogia e Jornalismo (Glaser, 1989, p. 16).

Para este fim, no caso da Didática, foi mantida a duração de um ano, com as mesmas disciplinas de 1939. Visando a concretização das finalidades anunciadas, novas reformulações foram efetuadas. No início de 1961, o Departamento de Pedagogia passou a ofertar os Cursos de Pedagogia, de Didática e de Orientação Educacional. Porém, a partir da Lei 4.024/61 (Lei de Diretrizes e Bases da Educação Nacional (LDB)) houve uma reorganização dos currículos.

\section{Quadro 2 - Disciplinas Obrigatórias dos Cursos do Departamento de Pedagogia - UFPR (1963)}

Didática - 1 ano

Didática Geral; Didática Especial; Psicologia Educacional; Adm. Escolar; Fund. Biológicos da Ed.; Fund. Psicológicos da Ed.

Pedagogia -4 anos

10: Psicologia da Ed. (Introd.); Sociologia Geral; Biologia Geral e Educacional; Estatística Geral

20: Sociologia da Ed.; História da Ed. (Antiga e Medieval); Adm. Escolar; Estatística Esco-lar; Teoria Escolar; Higiene Escolar

3: Psicologia da Ed. (Adolescência); História da Ed. (Moderna e Contemporânea); Filoso-fia da Ed.; Adm. Escolar; Teoria e Prática da Escola Média; Didática Geral

4º: História da Ed. (Brasil); Filosofia da Ed.; Psicologia da Aprendizagem;

Psicologia Dife-rencial; Didática - Prática de Ens.; Ed. Comparada; Introd. à

Orientação Educacional

Fonte: Adaptado de Glaser (1989).

Educação \& Realidade, Porto Alegre, v. 41, n. especial, p. 1441-1464, dez. 2016. 1447 
Estes currículos parecem ter sido uma tendência nacional, a partir da regulamentação da LDB e do Parecer 251/62, do Conselho Federal de Educação (CFE), que estabeleceu um currículo e duração mínimos para o Curso. No mesmo ano, o Parecer CFE 292 definiu:

[...] licenciatura como equivalente ao bacharelato, tornando-a obrigatória no contexto curricular de formação do professor.

Os mínimos curriculares fixados neste parecer para obtenção de licenciatura são:

Psicologia da Educação (adolescência e aprendizagem)

Didática

Elementos de Administração Escolar

Prática de Ensino sob forma de estágio supervisionado nas matérias que sejam objeto de uma formação profissional (Glaser, 1980, p. 16-17).

Desta forma, o modelo $3+1$ era fortalecido. No contexto pós-LDB e da ditadura civil-militar ${ }^{5}$, várias normas configuraram a Reforma Universitária $^{6}$, resultando em reorganização administrativa e pedagógica. No caso da UFPR, na primeira ${ }^{7}$ reestruturação, foi criada a Faculdade de Educação:

Em 22 de agosto de 1970, reuniram-se os Professores do Departamento de Pedagogia, a fim de estruturar o Setor de Didática e Prática de Ensino. Na ocasião o Chefe do Departamento de Pedagogia esclareceu que de acordo com o regulamento de reestruturação, o Curso de Pedagogia passaria a constituir a Faculdade Federal de Educação, o Departamento de Pedagogia seria desdobrado em vários departamentos, sendo um deles o de Didática e outro o de Prática de Prática de [sic] Ensino.

Em 4 de fevereiro de 1971, os Professores se reuniram a fim de constituir o Departamento de Didática e Estágio Supervisionado na Comunidade, sendo o mesmo denominado Setor e não Departamento, até que fosse implantada a Faculdade de Educação. 'Didática seria ministrada em 60 horas e com estágio supervisionado na comunidade ou regência de classe. Quanto às licenciaturas, o setor deverá abranger cinco áreas: Ciências Humanas, Matemática, Letras, Ciências Naturais e Física' (Glaser, 1989, p. 22).

De acordo com Machado (1983), em 1971 a Faculdade de Educação contava com uma Coordenação do Curso de Pedagogia e uma Coordenação de Licenciaturas, responsáveis mais diretas pela discussão e proposições para formação de educadores.

Em relação à Reforma, uma segunda reestruturação da UFPR foi implementada em $1973^{8}$, criando o Setor de Educação, com os Departamentos: Teoria e Fundamentos da Educação; Métodos e Técnicas da Educação; Planejamento e Administração Escolar; e Biblioteconomia ${ }^{9}$.

1448 Educação \& Realidade, Porto Alegre, v. 41, n. especial, p. 1441-1464, dez. 2016. 
Vieira; Gonçalves

O Regimento do Setor estabeleceu os seguintes cursos de graduação:

Art. 96 - Os cursos de graduação vinculados ao Setor são os seguintes:

I - Pedagogia, nas seguintes habilitações:

a) Administração Escolar

b) Orientação Educacional

c) Supervisão Escolar

d) Magistério de Disciplinas Pedagógicas do 2o grau

e) Habilitação ao Magistério - Formação Pedagógica para:

1 - Área de Estudos Gerais de $1^{\circ}$ e $2^{\circ}$ graus

2 - Disciplinas Especializadas de $2^{\circ}$ grau

II - Biblioteconomia (Universidade Federal do Paraná; Setor de Educação, 1973).

Também houve consequência da legislação educacional do período quanto ao Curso de Pedagogia, especificamente:

Em 1969, a Resolução CFE n. 2/69 e Parecer CFE n. 252/69, passam a regulamentar o Curso de Pedagogia. O Parecer fixava os mínimos de currículo e duração do Curso, e visava à formação ou de professores para o ensino normal ou de especialistas para as atividades de orientação educacional, administração escolar, supervisão escolar e inspeção escolar, criando habilitações para a formação de profissionais para atuarem em cada uma das atividades específicas (Costa, 2012, p. 26).

Por sua vez, como parte das reformas educacionais da época, a do $1^{\circ}$ e $2^{\circ}$ graus, estabelecida pela Lei 5.692/71, trazia a formação necessária para o exercício do magistério:

Art. 30. Exigir-se-á como formação mínima para o exercício do magistério:

a) no ensino de $1^{\circ}$ grau, da $1^{\text {a }}$ à $4^{\text {a }}$ séries, habilitação específica de $2^{\circ}$ grau;

b) no ensino de $1^{\text {o }}$ grau, da $1^{\text {a }}$ à $8^{\text {a }}$ séries, habilitação específica de grau superior, ao nível de graduação, representada por licenciatura de $1^{\circ}$ grau obtida em curso de curta duração;

c) em todo o ensino de $1^{\circ}$ e $2^{\circ}$ graus, habilitação específica obtida em curso superior de graduação correspondente a licenciatura plena (Brasil, 1971).

Com base nestas diretrizes, a reformulação curricular implementada no Curso de Pedagogia em 1972, “[...] caracterizou-se pela criação das seguintes Habilitações: Supervisão Escolar, Orientação Educacional, Administração Escolar, mais a formação para o Magistério das disciplinas pedagógicas do $2^{\circ}$ grau" (Universidade Federal do Paraná; Setor de Educação, 2014). Em decorrência e em consonância com esta legislação, o currículo do Curso de Pedagogia foi reformulado ${ }^{10}$, e aprovado em 1975.

Educação \& Realidade, Porto Alegre, v. 41, n. especial, p. 1441-1464, dez. 2016. 1449 
FormaçãodeProfessoresnoSetordeEducaçãodaUniversidadeFederaldoParaná(1938-2010)

\section{Quadro 3 - Currículo do Curso de Pedagogia, nas suas Habilitações (1975)}

\begin{tabular}{|c|}
\hline $1^{\circ}$ ciclo - básico - Disciplinas Nucleares \\
\hline $\begin{array}{l}\text { Problemas Fundamentais de Filosofia; Introd. à Psicologia; Introd. à } \\
\text { Antropologia Cultural; Sociologia Geral I; Estatística I }\end{array}$ \\
\hline Disciplinas Básicas Específicas \\
\hline $\begin{array}{l}\text { Psicologia da Ed. I, II e III; História da Ed. I, II e III; Filosofia da Ed. I, II e III; } \\
\text { Sociolo-gia da Ed.; Biologia Educacional I }\end{array}$ \\
\hline $2^{\circ}$ ciclo - Profissionalizante - currículo mínimo - tronco comum \\
\hline $\begin{array}{l}\text { Estatística Aplicada à Ed.; Didática I; Metod. do Ens. de } 1^{\circ} \text { grau I; Prática de Ens. } \\
\text { na Escola de } 1^{\circ} \text { grau (Estágio); Estrut. e Funcionamento do Ens. de } 1^{\circ} \text { grau; e de } 2^{\circ} \\
\text { grau }\end{array}$ \\
\hline Disciplinas e atividades complementares obrigatórias \\
\hline $\begin{array}{l}\text { Estudo de Problemas Brasileiros I e II; Ed. Comparada I; Legislação do Ens.; } \\
\text { Prática de Ens. de Disciplinas Pedagógicas na Escola de } 2^{\circ} \text { grau (Estágio) }\end{array}$ \\
\hline Habilitação Administração Escolar \\
\hline Disciplinas e atividades obrigatórias \\
\hline $\begin{array}{l}\text { Princípios e Métodos de Adm. Escolar I e II; Adm. da Escola de } 1^{\circ} \text { grau; Adm. da } \\
\text { Escola de } 2^{\circ} \text { grau; Estágio Supervisionado em Adm. Escolar }\end{array}$ \\
\hline Disciplinas complementares obrigatórias \\
\hline $\begin{array}{l}\text { Princípios e Métodos de Supervisão Escolar II; Supervisão da Escola de } 2^{\circ} \text { grau; } \\
\text { Currículos e Programas do Ens. de } 2^{\circ} \text { grau }\end{array}$ \\
\hline Habilitação Supervisão Escolar \\
\hline Disciplinas e atividades obrigatórias \\
\hline $\begin{array}{l}\text { Princípios e Métodos de Supervisão Escolar; Supervisão da Escola de } 1^{\circ} \\
\text { grau; Cur-rículos e Programas do Ens. de } 1^{\circ} \text { grau; Estágio Supervisionado em } \\
\text { Supervisão Es-colar }\end{array}$ \\
\hline Disciplinas complementares obrigatórias \\
\hline $\begin{array}{l}\text { Princípios e Métodos de Supervisão Escolar II; Supervisão da Escola de } 2^{\circ} \text { grau; } \\
\text { Currículos e Programas do Ens. de } 2^{\circ} \text { grau }\end{array}$ \\
\hline Habilitação Orientação Educacional \\
\hline Disciplinas e atividades obrigatórias \\
\hline $\begin{array}{l}\text { Princípios e Métodos de Orientação Educacional I; Orientação Educacional I; } \\
\text { Medi-das Educacionais I; Estágio Supervisionado em Orientação Educacional }\end{array}$ \\
\hline Disciplinas complementares obrigatórias \\
\hline $\begin{array}{l}\text { Princípios e Métodos de Orientação Educacional II; Orientação Educacional II; } \\
\text { Me-didas Educacionais II }\end{array}$ \\
\hline
\end{tabular}

Fonte: Resolução 46/75 CEP-UFPR (Universidade Federal do Paraná, 1975).

A principal mudança em relação aos currículos anteriores foi a inserção das habilitações, que fracionaram a formação e ampliaram significativamente o espaço das disciplinas relacionadas ao planejamento e à administração escolar, o que marcará a formação do pedagogo na UFPR a partir de então.

1450 Educação \& Realidade, Porto Alegre, v. 41, n. especial, p. 1441-1464, dez. 2016. 
Por sua vez, a Resolução CFE 09/6911, fixou os mínimos de conteúdo e duração a serem destinados à formação pedagógica nos cursos de licenciatura e estabeleceu as seguintes matérias pedagógicas: Psicologia da Educação, Didática, Estrutura e Funcionamento do Ensino de $2^{\circ}$ grau, além da Prática de Ensino na matéria que fosse objeto da habilitação profissional. A UFPR acompanhou a legislação, ofertando exatamente estas disciplinas como matérias de formação pedagógica nos currículos dos Cursos de Licenciatura.

Sobre essa questão, vários docentes do Setor apresentam sua visão geral da Educação, e os objetivos comuns a todas as Práticas de Ensino, apontando a necessidade de melhor preparação dos professores:

Todo professor é julgado pela capacidade de exercer com eficiência a sua profissão. No curso de Didática, o estudante adquire conhecimentos e princípios que o capacitam a fazer experiências e para que sejam efetuadas com êxito é necessário que resultem da ação conjunta do aluno-mestre e dos professores de Prática de Ensino. [...]

Pretendemos revolucionar a Prática de Ensino por meio de programas funcionais, que exigem do aluno-mestre a compreensão do processo fundamental de ensino/aprendizagem, conhecimentos dos problemas de ensino dentro de uma situação real e domínio de habilidades necessárias à orientação da aprendizagem dos alunos no $1^{\circ} \mathrm{e} 2^{\circ}$ graus [...] (Vecchia, 1972, p. 19).

Após discussões em âmbito regional e nacional, coordenadas pelo MEC, a respeito da "formação de recursos humanos para a educação" (Machado, 1983, p. 35) o Setor propôs um Curso Superior de Educação. De acordo com Colares essa proposta curricular privilegiava "a formação para o Magistério como a habilitação obrigatória”, e tornava “[...] optativas as demais habilitações de Administração Escolar, Orientação Educacional, Supervisão Educacional, cuja proposta não foi aprovada pelo Conselho de Ensino e Pesquisa, naquela ocasião". Ele seria voltado ao preparo de "um profissional de um campo educacional específico, desaparecendo a figura do licenciado" sendo que a ideia unificadora, para superação da fragmentação das habilitações, era de "[...] educador voltado às necessidades educacionais, também daqueles que não estão na escola" (1988, p. 71-72).

Nova proposta de currículo foi encaminhada em 1984 e aprovada pela Resolução 02/85-CEP, o que representou "o avanço possível na época” (Colares, 1988, p. 73). Sua integralização era de no mínimo 2.580 horas. 
Quadro 4 - Disciplinas Obrigatórias do Curso de Pedagogia (1985)

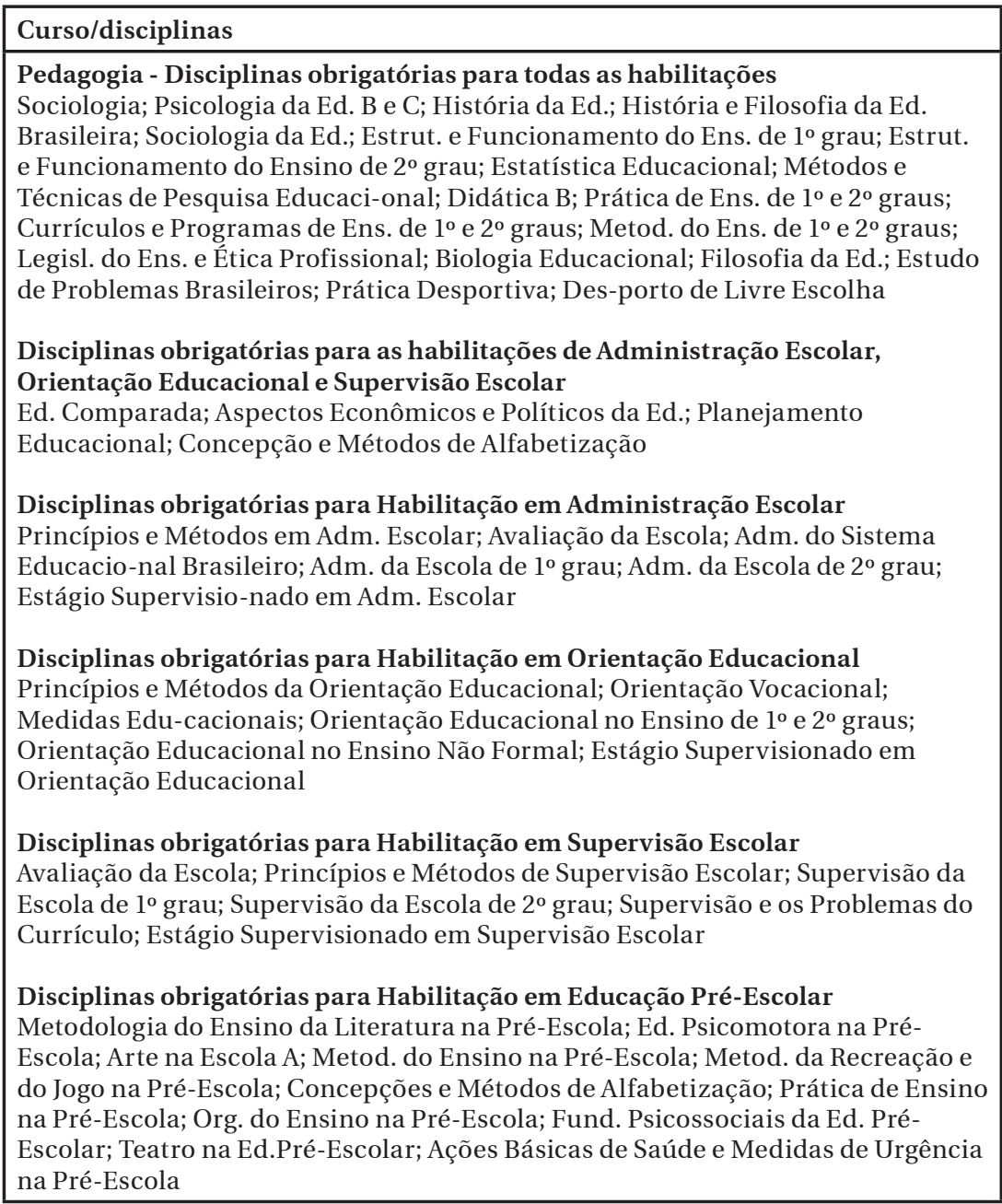

Fonte: Universidade Federal do Paraná (1985/1986, p. 93-94) ${ }^{12}$.

Em sua pesquisa, Colares (1988) identificou significativa crítica à fragmentação do trabalho do pedagogo, decorrente das habilitações. O currículo então vigente "[...] trouxe como avanço a compreensão quanto à existência de conteúdos comuns as diferentes habilitações, proporcionando uma certa articulação entre as mesmas" (Universidade Federal do Paraná; Setor de Educação, 1994, p. 25), com priorização da qualificação para a docência, uma vez que obrigatoriamente deveria ser cursada a habilitação em Magistério das Disciplinas Pedagógicas do Ensino de $2^{\circ}$ grau, e outra, de livre opção do estudante. Compreendia-se que esta habilitação obrigatória também prepararia para a docência no $1^{\circ}$ grau, incluindo $1^{\text {a }}$ a $4^{\text {a }}$ séries. 
A partir dos desafios da formação do pedagogo, identificados até então e potencializados por novas demandas, em 1994 foi encaminhada uma proposta de reformulação do currículo do Curso de Pedagogia da UFPR. As discussões desenvolvidas no Setor estavam em consonância com a tendência identificada por Bissolli da Silva (2011, p. 135), de terceiro período ${ }^{13}$ (de 1978 a 1999), de propostas relativas ao Curso de Pedagogia no Brasil, e que envolveu o processo de revisão da formação do educador.

A proposta apresentada em 1994 visou ao "resgate do processo pedagógico, na sua totalidade" (Universidade Federal do Paraná; Setor de Educação, 1994, p. 28-29):

A qualificação a ser desenvolvida, pelo novo Curso de Pedagogia, supõe, dessa maneira, uma sólida fundamentação científica, que articule as contribuições resultantes da abordagem do processo educacional pelas diferentes áreas do saber científico [...]. Supõe ainda o estudo detido e cuidadoso dos princípios e procedimentos técnico-metodológicos necessários ao adequado desempenho no trabalho educacional, quer no plano dos Sistemas de Ensino, quer no âmbito das Unidades Escolares. Acrescenta-se, ainda, a importância de que os egressos do Curso de Pedagogia estejam de posse do instrumental associado as tarefas que serão cumpridas pelo pedagogo enquanto organizador da unidade pedagógica, necessária ao trabalho educativo [...]. Entende-se que a qualificação do pedagogo deve abranger a preparação para a docência em dois diferentes níveis. De um lado, a formação, já clássica, destinada ao magistério das disciplinas pedagógicas do Ensino Médio e, de outro, a formação para a atuação como docente de $1^{\mathrm{a}}$ a $4^{\mathrm{a}}$ série do Ensino Fundamental.

Desta forma, o currículo obrigatório do Curso ficou estabelecido, com uma extensa, mas única habilitação. 


\section{Quadro 5 - Disciplinas Obrigatórias do Curso de Pedagogia - Habilitação Magistério das Séries Iniciais e das Disciplinas Pedagógicas do Ensino de $2^{\circ}$ Grau e na Função de Pedagogo (1996)}

$1^{\circ}$ - Sociologia; Estrut. e Funcionamento da Ed. Infantil e do Ensino Fundamental A; Prática Pedagógica A: Extensão Escolar; Fund. da Ed. de Jovens e Adultos I; Fund. da Ed. Infantil I; Psicologia da Ed. E; História da Ed. B; Filosofia da Ed. B; Biologia Educacional B

$2^{\circ}$ - Prática Pedagógica B: Introd. à Pesquisa Educacional; Didática E; Estrut. e Funcionamento do Ens. Médio e da Ed. Profissional; Sociologia da Ed.; Psicologia da Ed. F; História da Ed. C; Filosofia da Ed. C

$3^{\text {o }}$-Metodologias do Ensino: de Língua Portuguesa, de História, das Ciências Naturais, da Matemática I, de Geografia, de Artes, da Educação Física I, das Disciplinas Pedagógicas do curso de Magistério I; Alfabetização A; Prática Pedagógica C: Estágio em Docência de $1^{\circ}$ e $2^{\circ}$ graus; Estrut. e Funcionamento do Ens. de Jovens e Adultos; Ed. e Trabalho A; Concepções e Métodos do Trabalho Pedagógico A

$4^{\text {o }}$ - Tecnologia Aplicada à Ed. I; Ed. Comparada; Políticas e Planejamento da Ed. no Brasil A; Organização do Trabalho Pedagógico na Escola A; Medidas Educacionais e Avaliação Escolar A; O trabalho pedagógico na Ed. Não-Escolar A; Prática Pedagógica D: Estágio Supervisionado na Org. Escolar; Currículos e Programas A; Fund. Ed. Especial I.

Fontes: Resoluções CEPE-UFPR 15/96; 26/99; $90 / 00$ (Universidade..., 1996a; 1996b; 1996c).

Neste currículo, a carga horária em disciplinas obrigatórias somava 2.370 horas; mais 60 horas de optativas. Destacamos a ampliação da carga horária e do número das Metodologias de Ensino, contemplando áreas de conhecimento específicas, que até então não existiam no currículo, como uma das estratégias para o fortalecimento da ênfase no preparo para a docência.

Com a promulgação da Lei 9.394/96, foi estabelecida norma para a obrigatoriedade da formação do professor em nível superior para as séries iniciais (artigo 62):

A formação de docentes para atuar na educação básica far-se-á em nível superior, em curso de licenciatura, de graduação plena, em universidades e institutos superiores de educação, admitida, como formação mínima para o exercício do magistério na educação infantil e nas quatro primeiras séries do ensino fundamental, a oferecida em nível médio, na modalidade Normal (Brasil, 1996).

Bissolli da Silva (2011, p. 136) caracteriza este como o quarto período da história do Curso de Pedagogia no Brasil, até os dias atuais, que representa

[...] o confronto entre os fundamentos paralegais defendidos pelas entidades de profissionais da educação e as orientações que a Câmara de Educação Superior do Conselho Nacional de Educação, na tentativa de retomada do controle sobre a reformulação do curso de Pedagogia, tenta impor como seus fundamentos legais.

1454 Educação \& Realidade, Porto Alegre, v. 41, n. especial, p. 1441-1464, dez. 2016. 
Uma consequência da LDB, com a obrigatoriedade de que, até 2010, todos os docentes que atuavam na Educação Básica deveriam ter qualificação em nível superior, foi a criação, no Setor de Educação da UFPR, do Curso de Pedagogia na modalidade a distância semipresencial, no ano $2000^{14}$. De acordo com Sá (2003, p. 174), ele seguia “[...] um modelo de educação a distância semipresencial, sendo que sua carga horária prevê $30 \%$ de encontros presenciais e $70 \%$ de estudos a distância, assistida por acompanhamento pedagógico e orientação acadêmica".

Em 2002 o MEC e o CNE regulamentaram as Diretrizes Curriculares Nacionais para a formação de professores da Educação Básica, em cursos de licenciatura, de graduação plena em nível superior (Parecer CNE 01/2002 e Resolução CNE 01/2002) ${ }^{15}$, que passaram a orientar discussões de reformulações de currículos.

Neste mesmo ano teve início, no Setor de Educação, a discussão para reformulação do currículo do Curso de Pedagogia presencial, tendo em vista as novas normativas ${ }^{16}$. No processo foram desenvolvidas ações de avaliação do currículo vigente, das quais destacamos a seguinte constatação: havia “[...] necessidade de superação da fragmentação presente no Setor de Educação a fim de viabilizar um trabalho pedagógico realmente coletivo de concretização da proposta curricular vigente e dos necessários ajustes" (Universidade Federal do Paraná; Setor de Educação, 2007, p. 11).

Desta forma, buscando superar desafios, a concepção que orientou a proposta de reformulação foi a de pedagogo unitário, já anunciada no currículo de 1996:

[...] da natureza do trabalho pedagógico, retoma-se a ideia de pedagogo unitário, presente no currículo de Pedagogia de 1996. O conceito de pedagogo unitário aparece naquela formulação, vinculado à superação das habilitações (orientação educacional, supervisão escolar e administração escolar) e apontando para a formação do pedagogo para atuar preferencialmente no âmbito escolar. [...]

Assim, nesta proposta, a concepção de pedagogo unitário é ampliada, de um lado, pelo campo de atuação em espaços escolares e não escolares e, de outro, para uma atuação voltada às demandas geradas pelas transformações atuais referentes à evolução da ciência, da tecnologia, do trabalho e das relações humano-sociais. Assim, impõe-se ao pedagogo o enfrentamento do complexo contexto atual que implica na compreensão das questões sócio-culturais, cognitivas, político-econômicas, profissionais e valorativas (ético-formativas), que se tornam categorias para caracterizar seus posicionamentos e atuação (Universidade Federal do Paraná; Setor de Educação, 2007, p. 35-36, grifos no original).

Considerando essas questões e proposições, o currículo do Curso de Pedagogia presencial foi aprovado em 2007. Nele, podemos ressaltar

Educação \& Realidade, Porto Alegre, v. 41, n. especial, p. 1441-1464, dez. 2016. 1455 
elementos distintos dos anteriores: a inserção do Trabalho de Conclusão de Curso; a significativa ampliação da carga horária de disciplinas optativas; a ampliação do tempo de estágio, para 480h; e a expansão do Curso para cinco anos. Porém, no geral, houve muitas permanências.

Quadro 6 - Disciplinas Obrigatórias do Currículo Pleno do Curso de Pedagogia Presencial, na Habilitação: magistério da educação infantil, magistério dos anos iniciais do ensino fundamental e na função de pedagogo (2007)

\begin{tabular}{|c|}
\hline Pedagogia -5 anos \\
\hline $\begin{array}{l}1^{0} \text { - Filosofia da Ed. I; História da Ed. I; Biologia Educacional; Função Social do Pe- } \\
\text { dagogo; Organização e Gestão da Ed. Básica I; Organização e Gestão da Ed. Básica } \\
\text { II; Fund. da Ed. Infantil I; Pesquisa Educacional; Fund. da Ed. Especial }\end{array}$ \\
\hline $\begin{array}{l}2^{\circ} \text { - Filosofia da Ed. II; História da Ed. II; Sociologia da Ed.; Psicologia da Ed. I; Me- } \\
\text { tod. de Ens. da Ed. Infantil; e de Ensino de Artes; Didática; Ed. de Jovens e Adultos; } \\
\text { Ed. e Trabalho }\end{array}$ \\
\hline $\begin{array}{l}3^{\circ} \text { - Prática Pedagógica A - Estágio em Docência na Ed. Infantil; Metod. de Ens. } \\
\text { de História; e da Língua Portuguesa; Psicologia da Ed. II; Comunicação em Língua } \\
\text { Brasileira de Sinais (Libras); Políticas Educacionais; Alfabetização; Trabalho Peda- } \\
\text { gógico em Espaços Não Escolares; Estudos da Infância }\end{array}$ \\
\hline $\begin{array}{l}4^{\circ} \text { - Prática Pedagógica B - Estágio em Docência nos Anos Iniciais do Ensino Fun- } \\
\text { damental; Metod. de Ens. de Matemática; de Geografia; de Educação Física; de } \\
\text { Ci-ências; Currículo: Teoria e Prática; Tópicos Especiais em Psicologia da Ed. ; } \\
\text { Avalia-ção Educacional }\end{array}$ \\
\hline $\begin{array}{l}5^{\circ} \text { - Prática Pedagógica C - Estágio Supervisionado na Org. Escolar; Org. do Traba-lho } \\
\text { Pedagógico; Ed., Tecnologia e Cultura das Mídias; Trabalho de Conclusão de Curso }\end{array}$ \\
\hline
\end{tabular}

Fonte: Universidade Federal do Paraná; Setor de Educação (2007) ${ }^{17}$.

O Curso ficou com 2.800 horas de disciplinas obrigatórias; 300 horas de optativas; 100 horas de atividades formativas. Essas mudanças decorreram da tentativa de contemplar as diversas funções correspondentes à concepção de pedagogo unitário, presentes na múltipla - embora única - habilitação.

Ainda em 2006, o Setor voltou a discutir a oferta de Curso de Pedagogia a distância ${ }^{18}$ e no início de 2009 foi iniciada a oferta de novas turmas, atendendo a seis polos. Este Curso, também ofertado em 2000, envolve as disciplinas apresentadas no quadro a seguir: 
Quadro 7 - Disciplinas do Curso de Licenciatura Plena em Pedagogia EaD - Magistério da Educação Infantil e Anos Iniciais do Ensino Fundamental

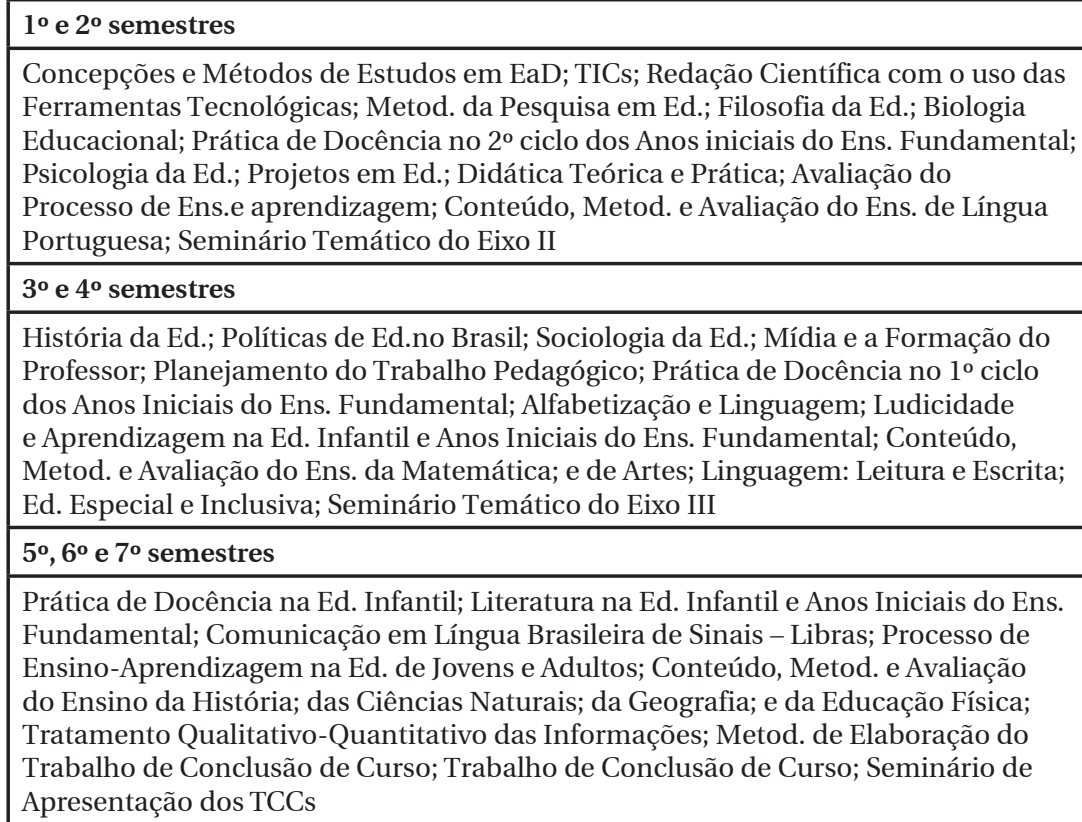

História da Ed.; Políticas de Ed.no Brasil; Sociologia da Ed.; Mídia e a Formação do Professor; Planejamento do Trabalho Pedagógico; Prática de Docência no $1^{\circ}$ ciclo dos Anos Iniciais do Ens. Fundamental; Alfabetização e Linguagem; Ludicidade e Aprendizagem na Ed. Infantil e Anos Iniciais do Ens. Fundamental; Conteúdo, Metod. e Avaliação do Ens. da Matemática; e de Artes; Linguagem: Leitura e Escrita; Ed. Especial e Inclusiva; Seminário Temático do Eixo III

$5^{\circ}, 6^{\circ}$ e $7^{\circ}$ semestres

Prática de Docência na Ed. Infantil; Literatura na Ed. Infantil e Anos Iniciais do Ens. Fundamental; Comunicação em Língua Brasileira de Sinais - Libras; Processo de Ensino-Aprendizagem na Ed. de Jovens e Adultos; Conteúdo, Metod. e Avaliação do Ensino da História; das Ciências Naturais; da Geografia; e da Educação Física; Tratamento Qualitativo-Quantitativo das Informações; Metod. de Elaboração do Trabalho de Conclusão de Curso; Trabalho de Conclusão de Curso; Seminário de Apresentação dos TCCs

Fonte: Universidade Federal do Paraná; Setor de Educação (2014).

O Curso de Pedagogia EaD tem carga horária de 2.656 horas/aula na modalidade a distância, 664 horas/aula na modalidade presencial e 100 horas de atividades formativas. Ele difere do Curso de Pedagogia presencial ofertado, na medida em que seu foco formativo é voltado para a docência.

Em relação às demais licenciaturas ${ }^{19}$, atendidas pelo Setor - treze, a saber: Artes Visuais, Ciências Biológicas, Ciências Sociais, Educação Física, Enfermagem, Filosofia, Física, Geografia, História, Letras, Matemática, Música e Química - a discussão sobre formação de professores continuava sendo desenvolvida e aperfeiçoada, agregando também as novas demandas decorrentes das normativas do MEC e do CNE.

No documento Reformulação Curricular das Licenciaturas $(2010)^{20}$, o Setor aponta e faz a crítica à permanência do modelo $3+1$, destacando que mesmo a tentativa de que a formação pedagógica ocorra ao longo do curso de licenciatura, e não somente concentrada em um último ano, não garante "[...] a superação da dicotomia entre a formação pedagógica e a formação específica, lógica esta que, por sua vez, provoca, muitas vezes, uma hierarquização entre os saberes específicos do curso e os saberes pedagógicos" (Universidade Federal do Paraná; Setor de Educação, 2010, p. 2). Também, defende o desenvolvimento profissional de professores, e para tanto, propõe:

Educação \& Realidade, Porto Alegre, v. 41, n. especial, p. 1441-1464, dez. 2016. 1457 


\section{Quadro 8 - Proposta de Núcleos Formativos para os Currículos de Licenciatura da UFPR}

\begin{tabular}{|l|l|l|}
\hline Núcleo & Contribuição & Responsável (is) \\
\hline $\begin{array}{l}\text { 1. Formação } \\
\text { nas ciências de } \\
\text { referência }\end{array}$ & $\begin{array}{l}\text { Subsídios sobre epistemologia e conteúdos } \\
\text { específicos da área de conhecimento }\end{array}$ & $\begin{array}{l}\text { Setor ou } \\
\text { Departamento } \\
\text { específico } \\
\text { da área de } \\
\text { conhecimento }\end{array}$ \\
\hline $\begin{array}{l}\text { 2. Formação } \\
\text { nas ciências da } \\
\text { educação }\end{array}$ & $\begin{array}{l}\text { 'Fundamentos históricos, biológicos, } \\
\text { socioeconômicos, políticos, culturais, } \\
\text { humano que embasam a educação, tendo } \\
\text { como foco principal a instituição escolar e } \\
\text { seus desdobramentos. Compreende também } \\
\text { o caráter epistemológico das ciências da } \\
\text { educaçãoe asmúltiplasinterfaces doprocesso } \\
\text { educativo comas ciências de referência' (p.3). }\end{array}$ & $\begin{array}{l}\text { Setor de } \\
\text { Educação }\end{array}$ \\
\hline 3.Articulador & $\begin{array}{l}\text { Prática como componente curricular, } \\
\text { transcende 'os estágios eterácomofinalidade } \\
\text { promover a articulação das diferentes } \\
\text { práticas' (p. 3), que inclusive podem compor } \\
\text { com disciplinas teóricas. }\end{array}$ & $\begin{array}{l}\text { Setor de } \\
\text { Educação e } \\
\text { Departamentos } \\
\text { das ciências de } \\
\text { referência }\end{array}$ \\
\hline 4. Complementar & Atividades formativas diversas. & $\begin{array}{l}\text { Setor de } \\
\text { Educação, } \\
\text { mas não } \\
\text { exclusivamente }\end{array}$ \\
\hline
\end{tabular}

Fonte: adaptado de Universidade Federal do Paraná; Setor de Educação (2010).

No Núcleo 1 são previstas como disciplinas obrigatórias Psicologia da Educação, Políticas e Planejamento da Educação Brasileira, Didática e Metodologia do Ensino de...; e como optativa, Metodologia da Pesquisa Educacional. Já no Núcleo 3, a parte cabível ao Setor de Educação envolve as disciplinas de Organização do Trabalho Pedagógico, Processos Interativos na Educação, Prática de Docência (I e II), e Trabalho de Conclusão de Curso de Licenciatura (I e II).

Desta forma, observarmos o propósito de fortalecimento, aperfeiçoamento e incremento da formação de professores promovido pelo Setor, além de aproximação e maior envolvimento dos demais Departamentos e Coordenações de Curso, como corresponsáveis por esta formação. 


\section{Considerações Finais}

Ao longo deste artigo visamos analisar o processo de formação de professores em nível superior, considerando as continuidades e as descontinuidades institucionais, curriculares e de projeto formativo que marcaram os cenários da FFCL (1938), da Faculdade de Educação (1970) e do Setor de Educação (1973) da UFPR. Detalhamos o projeto de educação superior que visou e ainda visa intervir nas práticas educativas, na melhoria das condições da escola pública, pela via da formação de profissionais tecnicamente qualificados e politicamente compromissados.

A trajetória dos, hoje, denominados: Curso de Pedagogia e Setor de Educação, e da sua participação na formação pedagógica das demais Licenciaturas da UFPR, evidencia dilemas que são mais amplos do que o próprio Setor, ou seja, que caracterizam o campo educacional brasileiro e sua trajetória histórica. Estas considerações trazem algumas indicações que, embora neste momento limitadas e ensaísticas, poderiam constituir questões para pesquisa.

Em relação ao Setor, observamos que a formação de professores sempre foi sua ênfase e seu propósito fundamental, o que implica em diversos desafios. Porém, os caminhos pelos quais a dimensão pedagógica da formação docente foi historicamente constituída no Brasil, favorecem a manutenção de um habitus e de regras nos campos das demais áreas de conhecimento que ofertam cursos de licenciatura, de resistência (maior ou menor, conforme o Departamento e os docentes) ao diálogo e ao reconhecimento da relevância dessa formação e atuação profissional, o que também é percebido no Setor. A rigor, a essência do modelo $3+1$ permanece, embora as disciplinas pedagógicas não estejam concentradas em um único ano e busque-se construir um diálogo e um processo colaborativo em relação aos docentes e Departamentos das áreas de conhecimento específicas das Licenciaturas. Além disso, no caso do Setor de Educação, nas disciplinas de Metodologia de Ensino e de Prática de Docência ofertadas para as licenciaturas, os docentes são formados nas áreas específicas em que atuam, por exemplo, historiadores lidam com o curso de História, o que permite que sejam estabelecidos diálogos profícuos e fundamentados quanto à epistemologia e conhecimentos próprios da área envolvida, à Educação e à docência.

Os Cursos de Pedagogia presencial e a distância, enfrentam questões um pouco distintas. No Curso de Licenciatura Plena em Pedagogia EaD - Magistério da Educação Infantil e Anos Iniciais do Ensino Fundamental, a habilitação é bastante clara e a ênfase é a preparação para o magistério. Embora estabelecido e formalmente institucionalizado como um curso de graduação do Setor de Educação e da UFPR, ainda parece sofrer resistência por parte de docentes do Setor, mais relacionada à modalidade da oferta, do que ao currículo do Curso, porém gradativamente vem ganhando maior reconhecimento.

Educação \& Realidade, Porto Alegre, v. 41, n. especial, p. 1441-1464, dez. 2016. 1459 
No caso do Curso de Pedagogia presencial, na habilitação Magistério da Educação Infantil, Magistério dos Anos Iniciais do Ensino Fundamental e na função de Pedagogo, seu currículo vem passando mais uma vez por discussões para reformulação, com base em avaliações realizadas durante o processo de implantação do currículo de 2007.

Por outro lado, observamos, ao longo das várias reformulações do currículo, ao longo dos 75 anos de existência do Curso de Pedagogia presencial, como por exemplo, permanências, em especial quanto às disciplinas conhecidas como Fundamentos da Educação. As disciplinas relacionadas à formação do professor, como Didáticas e Matérias e Práticas no Ensino Primário (como consta no currículo de 1939), permanecem, embora as Metodologias tenham sido expandidas, bem como as Práticas de Docência, em especial a partir do currículo de 1996. A dimensão de formação em Administração Escolar, presente de forma tímida em 1939, também foi expandida, como pode ser observado no currículo de 1985, a partir das diversas habilitações ofertadas naquele contexto, permanecendo após a extinção destas. Outro aspecto que merece destaque é a ampliação, no currículo, da pesquisa educacional, presente desde 1985, mas que conta com o Trabalho de Conclusão de Curso, a partir do currículo de 2007. Houve ainda outras mudanças, inclusões, como a Educação Infantil, e de forma geral elas acompanharam as discussões, desafios e demandas presentes no contexto de construção dos diversos currículos pelos quais o Curso passou, incluindo a questão da identidade e função do pedagogo.

Um grande desafio é avançar no reconhecimento da concepção de prática de docência própria do Setor de Educação, quanto às suas especificidades, perante as demais instâncias da UFPR. Há na Universidade modelos em diversos formatos, e distintos propósitos e níveis de envolvimento dos docentes por eles responsáveis, o que torna difícil estabelecer padrões minimamente comuns, e pensar em normas e políticas que os contemplem, sem desvalorizar este importante momento formativo dos licenciandos. Isso envolve, ainda, os caminhos para a institucionalização de parcerias mais efetivas com as Secretarias Municipal e Estadual de Educação, que por vezes sofrem o agravante da descontinuidade de gestões, na UFPR, no próprio Setor, e nos governos municipal e estadual.

Entre desafios, tensões e proposições, o Setor de Educação vai traçando seus caminhos, seja em relação a questões maiores, concernentes ao campo educacional, à história, à política e à sociedade brasileiras, e particularmente quanto à Curitiba e ao Paraná, seja quanto às especificidades e trajetórias próprias da UFPR e da comunidade que constitui o Setor, como campo. Caminhos possíveis, múltiplos, que constituem a essência e a riqueza da Educação a ser promovida, no enfrentamento de algumas questões principais, identificadas neste trabalho como grandes permanências, embora reconfiguradas conforme os contextos históricos: a identidade e a formação necessária ao pedagogo que 
a Educação e a escola necessitam; a formação do professor, nas demais licenciaturas, para além do modelo $3+1$, e condizente com os desafios postos para a Educação e a escola, na contemporaneidade; a indissociabilidade entre ensino, pesquisa e extensão; e a formação continuada para educadores de forma ampla, em especial por meio da pesquisa e da extensão.

Recebido em 21 de agosto de 2016 Aprovado em 19 de outubro de 2016

\section{Notas}

1 Uma versão ampliada desse argumento que trata da criação da FFCL foi publicada anteriormente, no âmbito de um capítulo que trata da criação da UFPR, escrito por Carlos Eduardo Vieira e Névio de Campos. Este capítulo, intitulado Intelectuais eo processo de formação da Universidade Federal do Paraná (1912-1950), encontra-se publicado na obra organizada pelos Professores Renato Lopes Leite e Ricardo Costa de Oliveira, intitulada Reflexões: UFPR 100 anos (1912-2012). Uma segunda versão reduzida deste argumento e do processo de implantação do Curso de Pedagogia e do Setor de Educação na UFPR foi publicada no livro Setor de Educação e Curso de Pedagogia na Universidade Federal do Paraná (1938-2014): histórias, memórias e desafios contemporâneos (2016), organizado por Carlos Eduardo Vieira e Nadia Gaiofatto Gonçalves.

2 Além do Pe. Ballarin, o Pe. Luiz Gonzaga Miele exerceu posição de destaque na formação do laicato curitibano.

3 O Curso de Pedagogia foi reconhecido pelo Decreto 5.756 de 04/06/1940 (Brasil, 1940), e o de Didática pelo Decreto 15.719, de 31/03/1944 (Brasil, 1944).

4 De acordo com Glaser (1980) este curso não chegou a funcionar.

5 De acordo com Gonçalves e Ranzi (2012).

6 As Leis 4.881-A/65 e 5539/68 (Brasil, 1965; 1966); os Decretos-Leis 53/66 e 252/67 (Brasil, 1966; 1967); e a Lei 5.540/68 (Brasil, 1968).

7 Por meio do Estatuto da UFPR, aprovado pelo Conselho Universitário em 02/10/1969.

8 Por meio do Decreto 72.782, de 12/09/1973 (Brasil, 1973).

9 Este Departamento foi transferido para o Setor de Ciências Humanas, Letras e Artes, em 1987. Segundo o professor Odilon C. Nunes, sua agregação ao Setor de Educação ocorreu, pois havia um número mínimo de unidades que deveriam compor um Setor.

10 Para Bissolli da Silva (2011, p. 135), na história do Curso de Pedagogia este período é caracterizado por indicações, vai de 1973 a 1977, e envolve as Indicações do Conselheiro Valnir Chagas (do CFE), "visando à reestruturação global dos Cursos Superiores de formação do Magistério no Brasil”.

11 De acordo com Bissolli da Silva (2011), abordando a história do Curso de Pedagogia no Brasil, o primeiro período, de 1939 a 1972, seria de regulamentações.

12 Currículo complementado pelas Resoluções CEP 08/85; 17/85; e 48/93.

13 Para Bissolli da Silva, o primeiro período (1939-1972) seria de regulamentações do Curso de Pedagogia, e o segundo (1973-1977) seria de indicações para este Curso.

14 Credenciado pelo Parecer n..$^{358 / 2000-C N E}$, com funcionamento autorizado pelo MEC pela Portaria n. ${ }^{\circ}$ 576/2000.

Educação \& Realidade, Porto Alegre, v. 41, n. especial, p. 1441-1464, dez. 2016. 1461 
FormaçãodeProfessoresnoSetordeEducaçãodaUniversidadeFederaldoParaná(1938-2010)

15 Outros documentos relativos à formação de professores são os Pareceres CNE n.01/1999; 115/1999; 133/2001; 09/2001; 27 e28/2001; 18 e 19/2002; 01/2003; 04/2004.

16 Foram consideradas as seguintes normativas: Lei 9.394/96; Resolução CNE/CP 01/2002; Resolução CNE/CP 02/2002; Lei 10.436/2002; Resolução CNE/CP 01/2004; Decreto 5.626/2005; Parecer CNE/CP 05/2005; Parecer CNE/CP 03/2006; e Resolução CNE/CP nº 01/2006.

17 Este currículo sofreu ajustes posteriores, como os estabelecidos pelas Resoluções 02/12 e 11/12 CEPE.

18 A partir do Edital da Universidade Aberta do Brasil no 01/2006 - SEED/MEC 2006/2007.

19 Além das Pedagogias, presencial e a distância.

20 Com base nas diretrizes da LDB de 1996 e nas Diretrizes Nacionais para a Formação Inicial de Professores da Educação Básica (Resolução CNE/CP 01/2002), entre outros.

\section{Referências}

ANUÁRIO da Faculdade de Filosofia, Ciências e Letras do Paraná. Faculdade de Filosofia, Ciências e Letras do Paraná. Curitiba, 1940/1941.

ANUÁRIO da Faculdade de Filosofia, Ciências e Letras do Paraná. Curitiba: Faculdade de Filosofia, Ciências e Letras do Paraná, 1943.

BRASIL. Ministério da Educação. Decreto-Lei n. 1.190 de 04 de Abril de 1939. Dá organização à Faculdade Nacional de Filosofia. Diário Oficial da União, Rio de Janeiro, 06 abr. 1939. P. 7929.

BRASIL. Ministério da Educação. Decreto n. 5.756 de 04 de Junho de 1940. Concede reconhecimento aos cursos de Filosofia, Ciências Sociais, Geografia e História, Pedagogia e Química da Faculdade de Filosofia, Ciências e Letras do Paraná, com cede em Curitiba, Estado do Paraná. Diário Oficial da União, Rio de Janeiro, 10 jun. 1940. P. 10985.

BRASIL. Ministério da Educação. Decreto n. 15.719 de 31 de Maio de 1944. Concede reconhecimento ao curso de Didática mantido pela Faculdade de Filosofia, Ciências e Letras do Paraná. Diário Oficial da União, Rio de Janeiro, 10 jun. 1944. P. 10400.

BRASIL. Ministério da Educação. Decreto-Lei n. 53 de Novembro de 1966. Fixa princípios e normas de organização para as universidades federais e dá outras providências. Diário Oficial da União, Brasília, 21 nov. 1966. P. 13416.

BRASIL. Ministério da Educação. Decreto-Lei n. 252 de 28 de Fevereiro de 1967. Estabelece normas complementares ao Decreto-Lei no 53, de 18 de novembro de 1966, e dá outras providências. Diário Oficial da União, Brasília, 28 fev. 1967. P. 2443.

BRASIL. Ministério da Educação. Decreto n. 72.782 de 12 de Setembro de 1973. Aprova o Plano de Reestruturação da Universidade Federal do Paraná. Diário Oficial da União, Brasília, 13 set. 1973. P. 9167.

BRASIL. Ministério da Educação. Lei n. 4.024 de 20 de Dezembro de 1961. Fixa diretrizes e bases da Educação Nacional. Diário Oficial da União, Brasília, 27 dez. 1961. P. 11429.

BRASIL. Ministério da Educação. Lei n. 4.881-A de 06 de Dezembro de 1965. Dispõe sobre o Estatuto do Magistério Superior. Diário Oficial da União, Brasília, 20 dez. 1965. P. 13078.

BRASIL. Ministério da Educação. Lei n. 5.539 de 27 de Novembro de 1968. Modifica dispositivos da Lei número 4.881-A, de 6 de dezembro de 1965, que dispõe sobre o Estatuto do Magistério Superior, e dá outras providências. Diário Oficial da União, Brasília, 29 nov. 1968. P. 10369.

1462 Educação \& Realidade, Porto Alegre, v. 41, n. especial, p. 1441-1464, dez. 2016. 
BRASIL. Ministério da Educação. Lei n. 5.540 de 28 de Novembro de 1968. Fixa normas de organização e funcionamento do ensino superior e sua articulação com a escola média, e dá outras providências. Diário Oficial da União, Brasília, 28 nov. 1968. P. 10369

BRASIL. Ministério da Educação. Lei n. 5.692 de 11 de Agosto de 1971. Fixa diretrizes e bases para o ensino de $1^{\circ}$ e $2^{\circ}$ graus, e dá outras providências. Diário Oficial da União, Brasília, 12 ago. 1971. Disponível em: <http://presrepublica.jusbrasil.com. br/legislacao/128525/lei-de-diretrizes-e-base-de-1971-lei-5692-71>. Acesso em: 10 ago. 2014.

BRASIL. Ministério da Educação. Lei n. 9.394, de 20 de Dezembro de 1996. Estabelece as diretrizes e bases da educação nacional. Diário Oficial da União, Brasília, DF, 23 dez. 1996. P. 27833. Disponível em: <http://portal.mec.gov.br/arquivos/pdf/ldb. pdf >. Acesso em: 10 ago. 2014.

CAMPOS, Névio de. Intelectuais Paranaenses e as Concepções de Universidade (1892-1950). Curitiba: Editora UFPR, 2008.

COLARES, Aglair da Cruz. O Curso de Pedagogia da UFPR Frente ao Compromisso Social da Universidade: ensino, pesquisa e extensão. Dissertação (Mestrado em Educação) - Programa de Pós-Graduação em Educação, Universidade Federal do Paraná, Curitiba, 1988.

COSTA, Letícia Jensen de Oliveira. Diretrizes Curriculares Nacionais para o Curso de Pedagogia: das proposições oficiais às propostas curriculares. Dissertação (Mestrado em Educação) - Programa de Pós-Graduação em Educação, Universidade Federal do Paraná, Curitiba, 2012.

GLASER, Niroá Zuleika Rotta Ribeiro. Formação Pedagógica do Currículo nos Cursos de Licenciatura. 1980. Dissertação (Mestrado em Educação) - Programa de Pós-Graduação em Educação da UFPR, Curitiba, 1980.

GLASER, Niroá Zuleika Rotta Ribeiro. Meio Século de Educação na UFPR: uma crônica desde a "Faculdade de Filosofia, Ciências e Letras e Instituto de Educação Anexo" ao "Setor de Educação". Curitiba: Fundação da UFPR, 1989.

GONÇALVES, Nadia Gaiofatto; RANZI, Serlei Maria Fischer. Educação na Ditadura Civil-Militar: políticas, ideários e práticas (Paraná, 1964-1985). Curitiba: Editora UFPR, 2012.

MACHADO, Evelcy Monteiro. O Curso de Pedagogia da UFPR, segundo a Percepção de Alunos Egressos. 100 f. Dissertação (Mestrado em Educação) - Programa de Pós-Graduação em Educação da UFPR, Curitiba, 1983.

SÁ, Ricardo Antunes de. Licenciatura em Pedagogia - Séries Iniciais do Ensino Fundamental na Modalidade de Educação a Distância: a construção histórica possível na UFPR. Educar, Curitiba, n. 21, p. 173-204, 2003.

SALEM, Tânia. Do Centro Dom Vital à Universidade Católica. In: SCHWARTZMAN, Simon (Org.). Universidades e Instituições Científicas no Rio de Janeiro. Brasília: CNPq, 1982. P. 97-134.

SILVA, Carmem Silvia Bissolli da. Curso de Pedagogia no Brasil: uma questão em aberto. In: PIMENTA, Selma Garrido (Org.). Pedagogia e Pedagogos: caminhos e perspectivas. 3. ed. São Paulo: Cortez, 2011. P. 131-154.

UNIVERSIDADE Federal do Paraná. Catálogo da UFPR 1985/1986. Curitiba: Editora da UFPR, 1985/1986.

UNIVERSIDADE Federal do Paraná. Resolução 46/75 CEP. Fixa o Currículo Pleno do Curso de Pedagogia, nas suas habilitações Administração Escolar, Supervisão Escolar, Orientação Educacional e Magistério, e dá outras providências. Curitiba, 1975.

UNIVERSIDADE Federal do Paraná. Resolução 15/96 - CEPE. Estabelece o Currículo Pleno do Curso de Pedagogia, do Setor de Educação. Arquivo da Secretaria dos Órgãos Colegiados, Curitiba, 1996a.

Educação \& Realidade, Porto Alegre, v. 41, n. especial, p. 1441-1464, dez. 2016. 1463 
UNIVERSIDADE Federal do Paraná. Resolução 26/99 - CEPE. Aprova ajuste curricular no Curso de Pedagogia, aplicável à Resolução n.15/96-CEPE. Arquivo da Secretaria dos Órgãos Colegiados, Curitiba, 1996b.

UNIVERSIDADE Federal do Paraná. Resolução 90/00 - CEPE. Aprova ajuste curricular no Curso de Pedagogia, aplicável à Resolução n.15/96 e 26/99 - CEPE. Arquivo da Secretaria dos Órgãos Colegiados, Curitiba, 1996c.

UNIVERSIDADE Federal do Paraná. Setor de Educação. Ante-Projeto de Reformulação do Currículo do Curso De Pedagogia. Processo 23.075.22696/94-00 - SIE/ UFPR, Curitiba, 1994.

UNIVERSIDADE Federal do Paraná. Setor de Educação. Proposta de Reformulação Curricular para o Curso de Pedagogia, Curitiba, 2007. Disponível em: <http://www. pedagogia.ufpr.br/ppp.htm>. Acesso em: 22 ago. 2014.

UNIVERSIDADE Federal do Paraná. Setor de Educação. Reformulação Curricular das Licenciaturas. Curitiba, 2010. Mimeo.

UNIVERSIDADE Federal do Paraná. Setor de Educação. Regimento. Curitiba, 1973. Disponível em: <http://www.educacao.ufpr.br/wp-content/uploads/2011/11/RegimentoSetorED.pdf >. Acesso em: 15 out. 2014.

UNIVERSIDADE Federal do Paraná. Setor de Educação. Site oficial. 2014. Disponível em: <http://www.educacao.ufpr.br/>. Acesso em: 15 out. 2014.

VECCHIA, Ariclê et al. Planejamento e Orientação de Didática e Práticas de Ensino. Revista da Faculdade de Educação, Curitiba, n. 1, p. 17-20, 1972.

VIEIRA, Carlos Eduardo; CAMPOS, Névio de. Intelectuais e o processo de formação da Universidade Federal do Paraná (1912-1950). In: LEITE, Renato Lopes; OLIVEIRA, Ricardo Costa de (Org.). Reflexões: UFPR 100 anos (1912-2012). Curitiba: Editora UFPR, 2013. P. 15-46.

VIERA, Carlos Eduardo; GONÇALVES, Nadia Gaiofatto (Org.). Setor de Educação e Curso de Pedagogia na Universidade Federal do Paraná (1938-2014): histórias, memórias e desafios contemporâneos. Curitiba: Editora UFPR, 2016.

WACHOWICZ, Ruy Christovam. Universidade do Mate: história da UFPR. Curitiba: Editora UFPR, 2006.

WESTPHALEN, Cecília Maria. Faculdade de Filosofia, Ciências e Letras do Paraná: 50 anos. Curitiba: SBPH-PR, 1988.

WESTPHALEN, Cecília Maria. Universidade Federal do Paraná. Curitiba: SBPH-PR, 1987.

Carlos Eduardo Vieira realizou pós-doutorado nas Universidades de Stanford-EUA (2015) e Cambridge-UK (2008); Doutor em História e Filosofia da Educação (PUC-SP-1998). Professor Associado 4 na UFPR, atuando no Programa de Pós-Graduação em Educação, desde 1998. Presidente da Sociedade Brasileira de História da Educação (SBHE); Pesquisador do Conselho Nacional de Desenvolvimento Científico e Tecnológico (CNPq), desde 2002. E-mail: cevieira9@gmail.com

Nadia Gaiofatto Gonçalves possui Graduação e Mestrado em História (UNESP Assis), Doutorado (USP) e Pós-doutorado (UFRJ) em Educação. É professora associada da UFPR, docente do Departamento de Teoria e Prática de Ensino, do Programa de Pós-Graduação em Educação, Linha de História e Historiografia da Educação, e do Programa de Mestrado Profissional em Ensino de História.

E-mail: nadiagg@ufpr.br 